\title{
Effect of radius of curvature and spading frequency of spading machine on physical properties of soil
}

\section{RITU DOGRA, BALDEV DOGRA AND AJEET KUMAR}

See end of the Paper for authors' affiliation

Correspondence to :

\section{RITU DOGRA}

School of Renewable Energy

Engineering, Punjab

Agricultural University, LUDHIANA (PUNJAB) INDIA
-ABSTRACT : The effect of radius of curvature and spading frequency on various dependent variables, i.e. weighted mean clod size, soil bulk density, cone index and cone index ratio were studied. The experiments were conducted in soil having 15.7 per cent clay, 53.6 per cent silt, and 30.7 per cent sand. During experimentation, moisture content of soil was maintained between 13 and 14 per cent. The radius of curvature used were C1 (Flat), C2 $(15 \mathrm{~cm})$ and C3 $(30 \mathrm{~cm})$. Four levels of bite lengths viz., 4, 6, 8 and $10 \mathrm{~cm}$ at travel speed of $18.47 \mathrm{~cm} / \mathrm{sec}$ were selected for the study. These corresponded to four levels of spading frequencies namely F1 (1.85 cycles/s), F2 (2.31 cycles/s), F3 (3.08 cycles/s) and F4 (4.62 cycles/s). The spading frequency was determined by dividing the travel speed by the bite length. The dependent variables decreased with increase in radius of curvature and spading frequency. Weighted mean clod size, soil bulk density and soil cone index decreased with increase in spading frequency and radius of curvature. However, it increased with increase with blade width.

- KEY WORDS : Spading machine, Tillage, Radius of curvature, Spading frequency, Pulverization, Bulk density, Cone index

- HOW TO CITE THIS PAPER : Dogra, Ritu, Dogra, Baldev and Kumar, Ajeet (2017). Effect of radius of curvature and spading frequency of spading machine on physical properties of soil. Internat. J. Agric. Engg., 10(1) : 60-66, DOI: 10.15740/HAS/IJAE/10.1/60-66. 